\title{
SVN Ineseres \\ Loss of Wip1 aggravates brain injury after ischaemia/reperfusion by overactivating microglia
}

\author{
Feng Yan (D) , ${ }^{1,2}$ Xiang Cheng, ${ }^{3}$ Ming Zhao, ${ }^{3}$ Shenghui Gong, ${ }^{3}$ Ying Han, ${ }^{1,3}$ \\ Liping Ding, ${ }^{3}$ Di Wu, ${ }^{2}$ Yumin Luo, ${ }^{2}$ Wei Zuo, ${ }^{4}$ Lingling Zhu, ${ }^{3,5}$ Ming Fan, ${ }^{1,3}$ \\ Xunming $\mathrm{Ji}^{1}$
}

To cite: Yan F, Cheng X, Zhao M, et al. Loss of Wip1 aggravates brain injury after ischaemia/ reperfusion by overactivating microglia. Stroke \& Vascular Neurology 2021;6: e000490. doi:10.1136/svn-2020-000490

Received 8 July 2020 Revised 18 November 2020 Accepted 22 November 2020 Published Online First 15 January 2021
Check for updates

(C) Author(s) (or their employer(s)) 2021. Re-use permitted under CC BY-NC. No commercial re-use. See rights and permissions. Published by BMJ.

${ }^{1}$ Beijing Institute of Brain Disorders, Laboratory of Brain Disorders, Ministry of Science and Technology, Collaborative Innovation Center for Brain Disorders, Capital Medical University, Beijing, China ${ }^{2}$ Cerebrovascular Disease Research Laboratory, Xuanwu Hospital, Beijing, China

${ }^{3}$ Institute of Military Cognition and Brain Sciences, Academy of Military Medical Sciences, Beijing, China

${ }^{4}$ Department of Pharmacy, Peking Union Medical College Hospital, Dongcheng-qu, Beijing, China

${ }^{5}$ Co-Innovation Center of Neuroregeneration, Nantong University, Nantong, China

Correspondence to Professor Lingling Zhu; linglingzhuamms@126.com

\section{ABSTRACT}

Background and purpose The inflammatory response mediated by microglia/macrophages is closely related to cerebral ischaemia/reperfusion injury. Wild-type p53induced protein phosphatase 1 (Wip1), a serine/threonine phosphatase, is expressed in various tissues. A growing number of reports have suggested that Wip1 is a negative regulator of inflammation in peripheral tissue; however, its role in the central nervous system (CNS) remains unclear. This study aimed to clarify whether Wip1 can inhibit CNS inflammation by regulating microglia/macrophage functions after ischaemic injury.

Methods A model of middle cerebral artery occlusion and reperfusion was established in mice. CNS inflammation was simulated by lipopolysaccharide treatment of primary microglia. Laser speckle imaging was used to monitor regional cerebral blood flow. Behavioural outcomes were assessed with a TreadScan gait analysis system. TTC staining was used to evaluate the infarct volume, and western blotting and immunofluorescence staining were applied to detect the phenotypical transformation of microglia. ELISA was performed to detect the levels of inflammatory factors.

Results Wip1 expression was increased after ischaemia/ reperfusion. Wip1-knockout (KO) mice displayed more severe brain injury than wild-type mice, as indicated by aggravated motor dysfunction, greater brain infarct volumes and higher expression of inflammatory cytokines (interleukin-6 and tumour necrosis factor alpha) in the brain. We also found that Wip1 depletion increased microglial/macrophage activation in both in vitro and in vivo models, which all showed activation of microglia/ macrophages. Lentivirus- $P p m 1 d$ reversed the injury induced by Wip1-KO.

Conclusions Our results suggest that Wip1 may inhibit neuroinflammation by inhibiting microglial/macrophage activation after brain ischaemia/reperfusion injury.

\section{INTRODUCTION}

Brain ischaemic stroke is characterised by high morbidity worldwide. The absolute numbers and mortality of patients who had stroke have increased in recent years. ${ }^{1}$ Neuroinflammation is often observed in neurological diseases. $^{2-5}$ Resident microglia exist in heterogeneous cell populations that play roles in the development of the central nervous system (CNS) and surveillance of the immune system. The roles of microglia in regulating immunological functions are related to their activation status, which is referred to as the microglial phenotype. ${ }^{6} \mathrm{M} 1 \mathrm{microglia}$ primarily elicit proinflammatory and cytotoxic effects, whereas M2 microglia inhibit inflammation and promote tissue regeneration. ${ }^{8}$ The terms 'M1' and 'M2' will be used to describe macrophage phenotype polarisation in order to simplify data interpretation in the current article since the ontogeny and functional significance of microglia have not yet been characterised. ${ }^{9}$ Some endogenous stimulators, such as tau oligomers and superoxide dismutase, may continuously activate M1 microglia and downstream inflammatory reactions, ultimately resulting in irreversible neuron loss. However, with the development of single-cell transcriptomics, increasing evidence has shown that some microglia can express M1 and M2 markers at the same time. ${ }^{10}$ Although the boundaries between the M1 and M2 phenotypes are unclear, examination of proinflammatory and anti-inflammatory factors remains valuable. Controlling the activation states of microglia/macrophages and directly inhibiting proinflammatory factors are potential interventions to protect against the injury induced by ischaemic stroke. ${ }^{11}$

Wild-type p53-induced protein phosphatase 1 (Wip1), a member of the PP2C family, is a serine/threonine phosphatase encoded by the Ppm1d gene (https://www.ncbi.nlm. nih.gov, gene ID: 53892) and is expressed in several tissues. Wip1 is thought to be a target gene of p53 and exhibits a variety of biological functions in DNA repair, cell cycle progres$\operatorname{sion}^{12} 13$ and autophagy. ${ }^{14}$ Recent studies have illustrated a new function of Wip1 in immune modulation via regulation of the development and function of immune cells. Wip1 can also interact with some inflammatory signalling proteins, including nuclear factor kappa 
B (NF-kB) and p38 mitogen-activated protein kinase. ${ }^{15} 16$ These results suggest that Wip1 might play a key role in CNS inflammation.

However, the role of Wip1 in microglia after brain ischaemia/reperfusion injury is still unknown. Thus, the aim of our study was to investigate the role of Wip1 in regulating microglial/macrophage phenotypical transformation, as well as the possible underlying mechanisms.

\section{MATERIALS AND METHODS}

\section{Transient focal cerebral ischaemia/reperfusion model}

In our study, adult male C57BL/6 mice (19-22g) were purchased from Vital River Experimental Animal Laboratories (Beijing, China), and Wip1-knockout $(\mathrm{KO})$ mice were acquired from Dr Zhi-Cheng Xiao (Department of Anatomy and Developmental Biology, Monash University, Clayton, Australia). Anaesthesia was induced and maintained with $70 \% \mathrm{~N}_{2} \mathrm{O}$ and $30 \% \mathrm{O}_{2}$ mixed with $5 \%$ and $2 \%$ isoflurane. A transient focal cerebral ischaemia model was established via right middle cerebral artery occlusion (MCAO) for $60 \mathrm{~min}$ as described previously. ${ }^{17}$ Briefly, the right middle cerebral artery, the internal carotid artery and the external carotid artery were exposed. A small hole was cut, through which a nylon monofilament (diameter: $0.21 \mathrm{~mm}$; Doccol, California, USA) was inserted to block blood flow. Then, reperfusion was established by withdrawing the nylon monofilament. Rectal temperature was maintained at $37^{\circ} \mathrm{C}$ with a heating pad.

\section{Physiological parameters and laser speckle imaging}

A physiological pressure transducer coupled with a dataacquisition system (AD Instruments, Australia) was used to record the mean blood pressure (MBP) and heart rate. To determine whether the model was successfully established, a PeriCam PSI System (Perimed, Sweden) was used to monitor regional cerebral blood flow (rCBF) at three time points (before MCAO, after MCAO and during reperfusion). Changes in cerebral blood flow are expressed as percentages of the baseline (non-infarcted lateral cerebral blood flow).

\section{Neurological function assessment and infarct volume determination}

Neurological function was assessed at the indicated time points with a TreadScan gait analysis system. The TreadScan system captured video of the mouse footfalls and analysed the video. After euthanising the animals, the brains were removed and cut into thick slices. The slices were incubated with $1.5 \%$ 2,3,5-triphenyltetrazolium chloride (TTC, Sigma-Aldrich Chemical) for $10 \mathrm{~min}$. The infarct size in each slice was measured and analysed using Image J Analysis Software. Neurological function assessment and infarct volume determination were performed by an investigator blinded to the group assignments.

The infarct volume percentage was calculated with the following equation: infarct volume $(\%)=$ infarctvol/total contralateral hemisphere volume $\times 100 \%$.

\section{Intracerebroventricular injection of lentivirus-Ppm1d}

A $P p m 1 d$-overexpressing vector was prepared by GENEWIZ (Suzhou, China). The Ppm $1 d$ coding sequence was packaged into lentiviruses $\left(10^{8} \mathrm{TU} / \mathrm{mL}\right)$. Mice were randomly divided into four groups: the Wip1-KO+MCAO group, the Wip1-KO+lentivirus MCAO group, the Wip1$\mathrm{KO}+$ lentivirus-Ppm $1 d+\mathrm{MCAO}$ group and the wild type (WT)+lentivirus-Ppm1d+MCAO group (rescue group). Each mouse was placed in a stereotaxic frame for intracerebroventricular injection as described previously. ${ }^{18}$ Eight microlitres of a mixture of lentiviral particles containing the Ppm1d sequence or of control lentiviral particles was injected into the right lateral cerebral ventricle. MCAO was performed 7 days after administration.

\section{Western blot analysis}

The cortical proteins were separated on $6 \%-10 \%$ sodium dodecyl sulfate-polyacrylamide gel electrophoresis gels and transferred to Immobilon transfer membranes (Millipore) for 1.5 hour at $4^{\circ} \mathrm{C}$. The membranes were blocked in Tris Buffered Saline with Tween (TBST) with $10 \%$ milk for 2 hours at room temperature. Then, the membranes were incubated with primary antibodies overnight at $4^{\circ} \mathrm{C}$. Primary antibodies against Wip1 (1:500, Cell Signalling Technology), NF-кB p65 (1:1000, Cell Signalling Technology), phospho-NF-кB p65 (1:1000, Cell Signalling Technology), Bcl-2 (Santa Cruz Biotechnology) and Bax (1:1000, Cell Signalling Technology) were used in this study. We used anti-rabbit and anti-mouse antibodies (1:5000, Santa Cruz Biotechnology) as the secondary antibodies. Quantitative results were obtained and analysed using an enhanced chemiluminescence detection system by an investigator blinded to the group assignments.

\section{Primary cultures of microglia}

Primary mixed glial cells (isolated from WT or Wip1-KO mice) were cultured. Briefly, brain tissue was collected from mice within 24 hours of birth. Primary glial cells were obtained after 14 days of routine culture. Microglial cells were isolated from the primary mixed glial cells by shaking on a shaking table for 12 hours at $200 \mathrm{r} / \mathrm{min}$.

Primary microglia were seeded on 24-well plates at a density of $1 \times 10^{5}$ cells $/ \mathrm{mL}$ and were cultured in a $5 \%$ $\mathrm{CO}_{2}$ incubator at $37^{\circ} \mathrm{C}$. The primary microglial cells were divided into six groups: the WT sham group, the WT+lipopolysaccharide (LPS) group, the Wip1-KO sham group, the Wip1-KO+LPS group, the Wip1$\mathrm{KO}+$ lentivirus+LPS group and the rescue Wip1-KO+LPS group (Wip1-KO+lentivirus-Ppm1d+LPS).

\section{ELISA}

Brain tissues, peripheral blood and cell supernatants were collected to measure the levels of inflammatory factors, including interleukin (IL)-6 and tumour necrosis factor alpha (TNF- $\alpha$ ), using a mouse ELISA kit (Neobioscience Technology Company, Beijing, China) according to the manufacturer's instructions by an investigator blinded to the group assignments. 


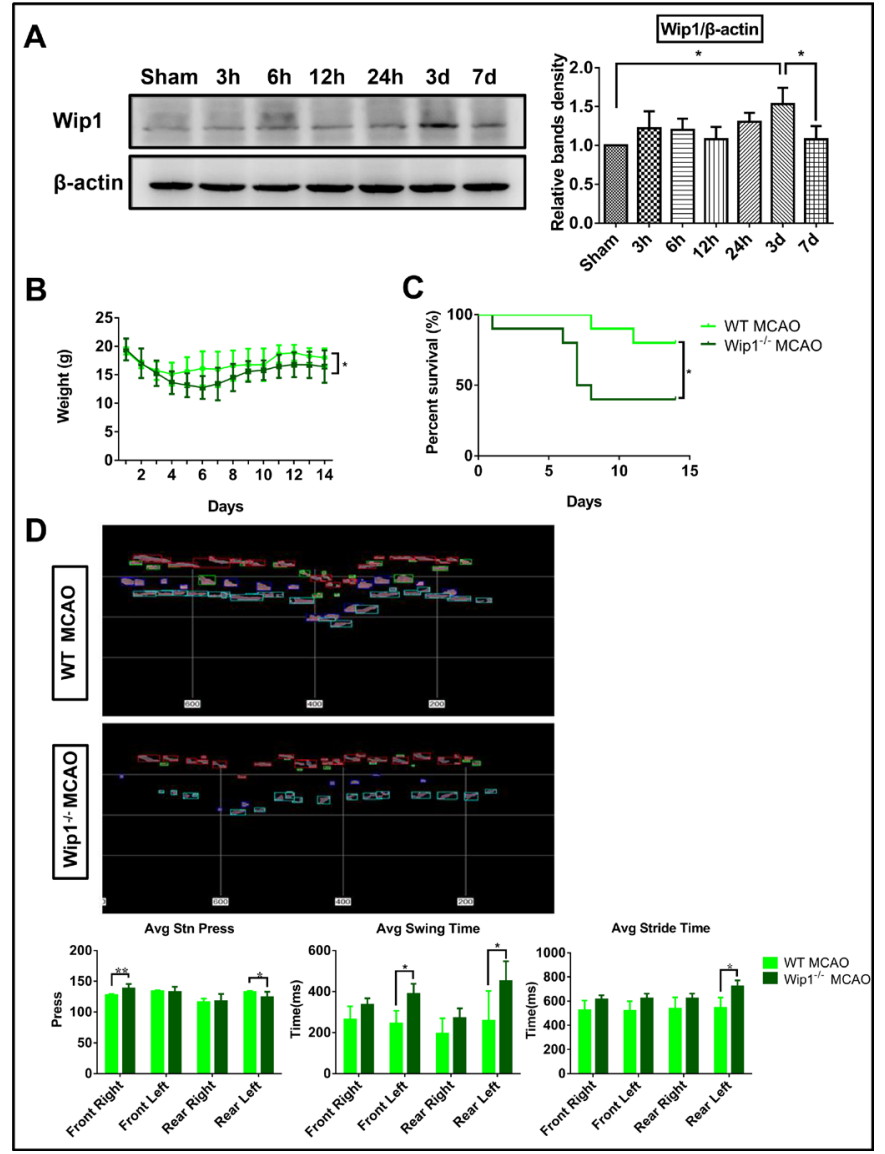

Figure 1 Wip1 was increased after ischaemia/reperfusion, and Wip1 depletion exacerbated neurological dysfunction. (A) Representative images (left) and quantification (right) of the expression of Wip1 at different time points after ischaemia/ reperfusion in WT mice. $n=3$ mice per group. Data are expressed as mean \pm SEM, ${ }^{*} p<0.05$. (B) Changes in weight after stroke at the indicated time points in mice. $n=10$ mice per group. Data are expressed as mean \pm SEM, ${ }^{*} p<0.05$ (Wip1-KO MCAO group vs WT MCAO group). (C) Changes in the survival rate after stroke at the indicated time points. $\mathrm{n}=10$ mice per group. Data are expressed as mean \pm SEM, ${ }^{*} p<0.05$ (Wip1-KO MCAO group vs WT MCAO group). (D) Top: representative images of motor function on the third day after reperfusion as determined by gait analysis in Wip1-KO and WT mice. Bottom: motor function was quantified on the third day after reperfusion by gait analysis in Wip1-KO and WT mice. $n=8$ mice per group. Data are expressed as mean \pm SEM; * $p<0.05,{ }^{* *} p<0.01$ (Wip1-KO MCAO group vs WT MCAO group). Avg, average; KO, knockout; MCAO, middle cerebral artery occlusion; Wip1, wild-type p53-induced protein phosphatase 1; WT, wild type.

\section{Immunofluorescence (IF) and cell counting}

The brain sections and fixed cells were placed in $3 \%$ $\mathrm{H}_{2} \mathrm{O}_{2} /$ methyl alcohol for $30 \mathrm{~min}$ and then placed in blocking solution for $30 \mathrm{~min}$. The brain sections and cells were incubated with primary antibodies (rat anti-CD16/ CD32 (1:500); BD Pharmingen, BD Biosciences; goat antiCD206 (1:200), R\&D Systems; rabbit anti-ionised calciumbinding adaptor molecule 1 (Iba-1) (1:200), Wako Chemicals, Virginia, USA) overnight at $4^{\circ} \mathrm{C}$ and immersed in a secondary antibody solution (Alexa Fluor 488-conjugated anti-mouse, Alexa Fluor 594-conjugated anti-goat and Alexa Fluor 594-conjugated anti-rat antibodies (1:200), Life Sciences, Paisley, UK) for 2 hours. For TUNEL (Terminal dexynucleotidyl transferase(TdT)-mediated dUTP Nick End Labeling) staining, the brain slices were incubated in working liquid (Roche) for 1 hour after blocking with $3 \%$ donkey serum. The brain sections and cells were covered with antifade medium containing DAPI (4',6-diamidino-2-phenylindole) images were acquired with a laser scanning confocal microscope (Nikon Ti-E, Japan). The number of positively stained cells per square millimetre was determined with NIH ImageJ software (Bethesda, Maryland, USA) by an investigator blinded to the experimental groups.

\section{STATISTICAL ANALYSIS}

The data were analysed using IBM SPSS Statistics V.21 and plotted using GraphPad Prism V.6.0 (GraphPad Software, California, USA). All normally distributed continuous variables are reported as the mean \pm SE. Significant differences between groups were assayed by one-way analysis of variance followed by the Dunnett or Least Significant Difference t-test. Generalised estimating equations were used to compare bodyweight differences among groups. The log-rank test was used to compare survival data, which were visualised with Kaplan-Meier curves. A p value of $<0.05$ was considered to indicate statistical significance.

\section{RESULTS}

Wip1 expression was increased after ischaemia/reperfusion Previous studies have reported that Wip1 plays an important role in CNS inflammation. Here, we first detected the expression of Wip1 after ischaemic brain injury. We found that brain Wip1 expression in mice was significantly (more than 1.5-fold) higher in the ischaemia model group than in the control group on the third day after MCAO; it then dramatically dropped to return to control levels by the seventh day (figure 1A), indicating that the expression of Wip1 is affected by ischaemic brain injury.

\section{Wip1 depletion aggravated neurological dysfunction after brain ischaemia/reperfusion}

To investigate the potential role of Wip1 in neurological function after ischaemia/reperfusion, Wip1-KO mice were used in this study. Body weight and the survival rate were recorded after brain ischaemia/reperfusion. We found that Wip1-KO mice showed an average bodyweight decrease of $7.8 \mathrm{~g} \quad(\mathrm{p}<0.05)$ (figure $1 \mathrm{~B})$. The mortality of Wip1-KO mice was $50 \%$ higher than that of WT mice on the 14th day after brain ischaemia/reperfusion (figure 1C).

To further detect the effect of Wip1 on motor function after brain ischaemia/reperfusion injury, motor function tests were performed using a TreadScan system to analyse the gaits of the mice on the third day after reperfusion. As 


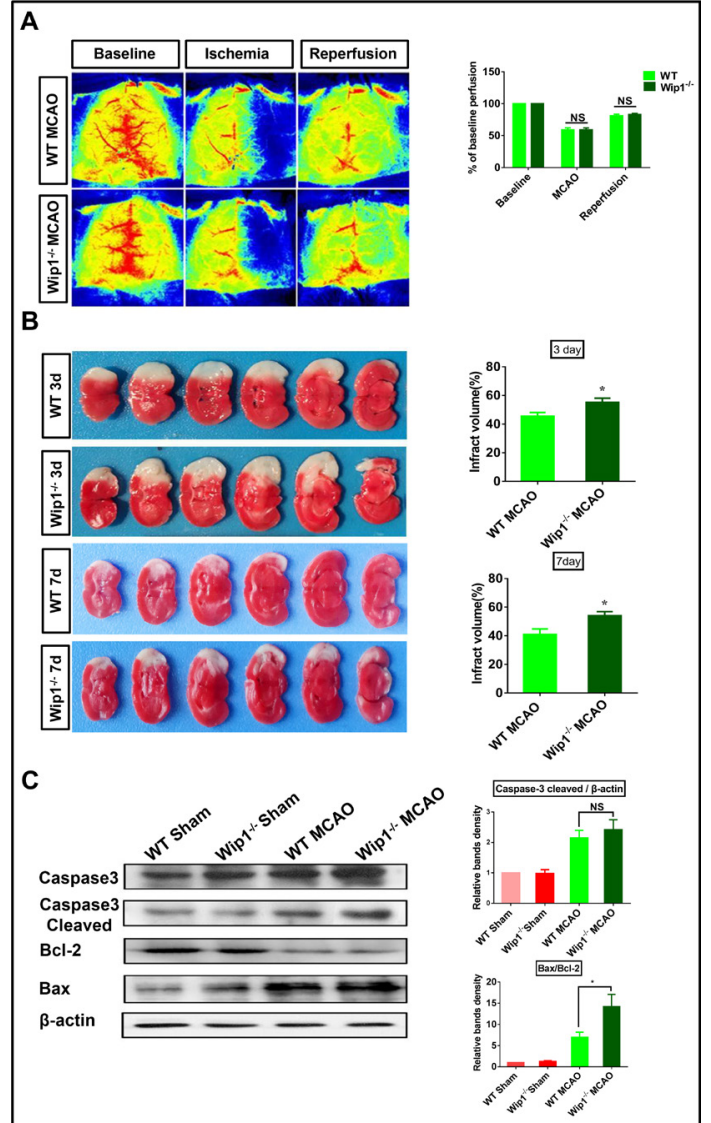

Figure 2 Wip1 deficiency increased infarct volumes and apoptosis after ischaemia/reperfusion. (A) Left: representative images of rCBF before cerebral ischaemia, 5 min after ischaemia and immediately after reperfusion. Right: quantification of rCBF. The results are expressed as the per cent change from baseline (non-infarcted lateral cerebral blood flow). Wip1-KO mice and WT mice showed similar rCBF values. $n=10$ mice per group (Wip1-KO MCAO group vs WT MCAO group). (B) Left: TTC staining of infarct regions in representative brain slices from different groups after 3 and 7 days of reperfusion. Right: quantification of infarct volumes with TTC staining in different groups. $n=10$ mice per group. ${ }^{*} p<0.05$ (Wip1-KO MCAO group vs WT MCAO group). (C) Left: representative western blot images of the expression of Bcl-2 and Bax. Right: quantification of Bax and Bcl-2 expression by western blot analysis. $n=3$ mice per group. Data are expressed as mean \pm SEM, ${ }^{*} \mathrm{p}<0.05$ (Wip1-KO MCAO group vs WT MCAO group). KO, knockout; MCAO, middle cerebral artery occlusion; NS, not significant; rCBF, regional cerebral blood flow; TTC, 2,3,5-triphenyltetrazolium chloride; Wip1, wild-type p53-induced protein phosphatase 1; WT, wild type.

shown in figure 1D, Wip1-KO mice exhibited substantially more serious motor function deficits after brain ischaemia/reperfusion. The Wip1-KO mice put more pressure on the ground using their right forelimb (10\%) and less pressure on the ground using their left hindlimb than the WT mice $(8.7 \%)$ after brain ischaemia/reperfusion. The swing time and stride time were much longer for the left forelimbs and left hindlimbs of Wip1-KO mice than for those of WT mice after brain ischaemia/reperfusion. However, no difference in the stride time of the right limbs was found between the two groups. Taken together, these results demonstrate that Wipl depletion aggravates motor dysfunction and decreased the survival rate in this mouse model of brain ischaemia/reperfusion injury.

Wip1-K0 and WT mice exhibited similar rCBF values and physiological parameters after brain ischaemia/reperfusion The MBP and heart rate were maintained at $81.6 \pm 11.0 \mathrm{~mm}$ $\mathrm{Hg}$ and $382.5 \pm 46.1$ beats/min, respectively, among the groups. rCBF was observed with a laser speckle contrast imager. In both groups, after occlusion of the right MCA, $\mathrm{rCBF}$ in the right MCA territories decreased to $59.2 \%$ of that in the left MCA territories. We found no obvious differences in rCBF between WT and Wip1-KO mice (figure 2A).

Wip1 deficiency increased infarct volumes and apoptosis after ischaemia/reperfusion

To assess whether Wip1 deficiency increased brain injury after reperfusion, a TTC assay was used to determine the infarct volume in the brain. As shown in figure 2B, we found that Wip1-KO mice exhibited 9.7\% and 13.0\% greater infarct volumes than WT mice after 3 and 7 days of reperfusion, respectively. The expression levels of the apoptosis-related proteins Bax and Bcl-2 were detected by western blotting. The results showed that the Bax/Bcl-2 ratio significantly increased with Wip1-KO (figure 2C), suggesting that Wipl depletion aggravates brain damage after brain ischaemia/reperfusion.

\section{Lentivirus-Ppm1d intracerebroventricular injection improved} brain injury after ischaemia/reperfusion

To further confirm the protective role of Wip1 in brain ischaemia/reperfusion, lentivirus-Ppm 1d was injected into the lateral ventricle, as shown in figure 3A. Wip1 expression was detected in Wip1-KO mice 7 days after injection. Three days after reperfusion, the motor function was evaluated, and then the animals were euthanised. We found that lentivirus-Ppm1d intracerebroventricular injection significantly reduced infarct volumes in Wip1-KO mice and WT mice compared with Wip1-KO+MCAO mice and Wip1-KO+lentivirus MCAO mice. The infarct volume tended to be lower in the WT rescue group than in the Wip1-KO rescue group $(p>0.05)$ (figure $3 \mathrm{~B})$. We also found that lentivirus-Ppm1d injection improved motor function by reducing the left hindlimb swing time and stride time and the average pressure applied by the right forelimb (figure 3C). We also compared the numbers of TUNEL-positive cells among all three groups. We found that the proportion of TUNEL-positive cells in the Wip1-KO group was $67.7 \%$ higher than that in the WT group. In addition, the number of TUNEL-positive cells was significantly decreased in lentivirus-Ppm 1 d-injected Wip1-KO mice (the rescue group) (figure 3D).

Loss of Wip1 increased microglial activation and the levels of inflammatory cytokines after brain ischaemia/reperfusion

Recent studies have found that shifted polarisation of microglia plays an important role in brain injury. ${ }^{19}$ 


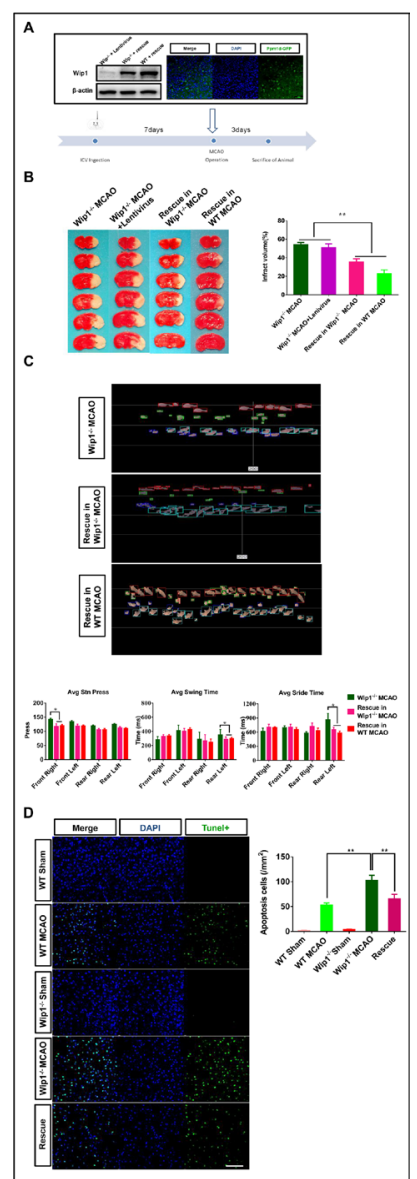

Figure 3 Intracerebroventricular (ICV) injection of lentivirus$P p m 1 d$ reduced ischaemic injury. (A) Diagram of the lateral cerebral ventricle injected with lentivirus-Ppm1d (representative western blot images of Wip1 expression after intracerebroventricular injection of lentivirus-Ppm1d and representative dual if staining after lateral cerebroventricular injection of lentivirus-Ppm1d). (B) Left: representative brain slices of infarct volumes with TTC staining in the different groups. Right: quantification of infarct volumes with TTC staining in the different groups. $\mathrm{n}=10$ mice per group. Data are expressed as mean \pm SEM, ${ }^{*} \mathrm{p}<0.01$ (Wip1KO MCAO+lentivirus-Ppm1d group vs Wip1-KO MCAO group and Wip1-KO MCAO+lentivirus group). (C) Top: representative images of motor function were evaluated 3 days after reperfusion by gait analysis in the Wip1-KO and rescue groups. Bottom: motor function was quantified on the third day after reperfusion by gait analysis in the Wip1-KO MCAO group and rescue group (Wip1-KO MCAO+lentivirusPpm1d group). $\mathrm{n}=10$ mice per group. Data are expressed as mean \pm SEM, * ${ }^{*}<0.05$ (Wip1-KO MCAO+lentivirus-Ppm1d group vs Wip1-KO MCAO group). (D) Left: representative images of TUNEL(Terminal dexynucleotidyl transferase(TdT)mediated dUTP Nick End Labeling)-positive cells in the different groups. Scale bar: $50 \mu \mathrm{m}$. Right: quantification of TUNEL-positive cells in the different groups. $n=6$ mice per group. Data are expressed as mean \pm SEM, ${ }^{\star *} \mathrm{p}<0.01$ (WT MCAO group vs Wip1-KO MCAO group; Wip1-KO MCAO group vs rescue group (Wip1-KO MCAO+lentivirus-Ppm1d group)). Avg, average; KO, knockout; MCAO, middle cerebral artery occlusion; TTC, 2,3,5-triphenyltetrazolium chloride; Wip1, wild-type p53-induced protein phosphatase 1; WT, wild type.
Wip1-KO is known to promote inflammatory factor release in the periphery and to aggravate CNS damage induced by LPS. ${ }^{20-23}$ We next explored whether the CNS damage aggravation in Wip1-KO mice was associated with a shift in the microglial phenotype after brain ischaemia/ reperfusion. The IF results showed that the number of activated microglia marked by CD16, CD206 and Iba-1 was significantly greater in the cortices of Wip1-KO mice than in those of WT mice after brain ischaemia/reperfusion (figure 4A,B). The levels of IL-6 and TNF- $\alpha$ in the peripheral blood and in the ischaemic cortex were then detected 3 days after brain ischaemia/reperfusion. Compared with that in the control group, the level of TNF- $\alpha$ in the cortex was increased, but no difference in the plasma TNF- $\alpha$ level was identified between the WT MCAO group and the Wip1-KO+MCAO group (figure 4C). However, the level of IL-6 in the brain was significantly greater in the Wip1-KO+MCAO group $(20.8 \mathrm{pg} / \mu \mathrm{g})$ than in the WT MCAO group $(11.7 \mathrm{pg} / \mu \mathrm{g}$ ) (figure $4 \mathrm{D})$. These data show that Wip1-KO can aggravate inflammation in the brain but not in the periphery after brain ischaemia/reperfusion. To further analyse the regulatory effect of Wip1 on the activation of microglia, the numbers of CD16-positive cells and CD206-positive cells were counted in the rescue group. As shown in figure $4 \mathrm{E}, \mathrm{F}$, Wip1 re-expression decreased the activation of microglia. The numbers of CD206-positive cells and CD16-positive cells were significantly lower in the re-expression group than in the Wip1-KO group.

\section{Wip1 deficiency enhanced inflammation in primary cultured} microglia after LPS stimulation

To determine the effect of Wip1 on microglial inflammation, primary microglial cells were isolated from newborn Wip1-KO mice and WT mice and stimulated with LPS for 12 hours. The sequence of Ppm1d was labelled with a fluorescent tag (Green Fluorescent Protein, GFP). The expression of GFP is shown in figure 5A. Double immunostaining showed that the percentage of M1-phenotype cells was 95\% higher among Wip1-deficient microglia than among WT microglia and was 50.3\% lower among microglia with Wip1 rescue than among Wip1-deficient microglia (figure 5B). Inflammatory cytokines in the culture solution were detected by ELISA. We found that the levels of the inflammatory cytokines IL- 6 and TNF- $\alpha$ were enhanced after stimulation with LPS in all groups. In addition, Wip1-KO microglia released more inflammatory cytokines than WT microglia. Lentivirus-Ppm1d was then added to the culture medium for 3 days in the Wip1-KO+LPS group. The data showed that excessive inflammation was significantly inhibited in the rescue group compared with the Wip1-KO group and that IL-6 and TNF- $\alpha$ levels were decreased by $56.3 \%$ and $55.8 \%$, respectively (figure 5C).

These data demonstrate that Wip1 plays an important role in regulating microglial activation, phenotypical transformation and the inflammatory reaction in microglial cells. 


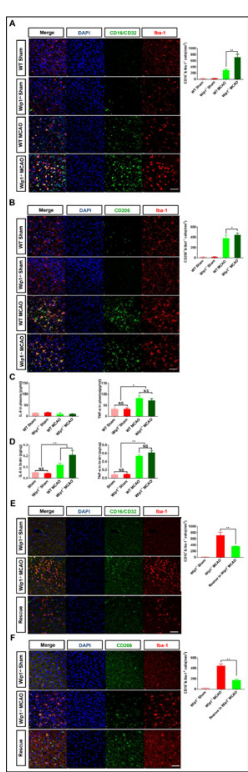

Figure 4 Loss of Wip1 promoted activation of microglia/ macrophages and increased inflammation in the brain after ischaemia/reperfusion, and injection of lentivirus-Ppm1d inhibited microglial activation and inflammation. (A) Left: representative dual if staining of CD16-positive and Iba1-positive cells in the cortex 3 days after brain ischaemia/ reperfusion. Scale bar: $50 \mu \mathrm{m}$. Right: quantification of CD16-positive and Iba-1-positive cells in the cortex 3 days after ischaemia/reperfusion. $n=6$ mice per group. Data are expressed as mean \pm SEM, ${ }^{* *} p<0.01$ (WT MCAO group vs Wip1-KO MCAO group). (B) Left: representative dual if staining of CD206-positive and Iba-1-positive cells in the cortex 3 days after brain ischaemia/reperfusion. Scale bar: $50 \mu \mathrm{m}$. Right: quantification of CD206-positive and lba-1-positive cells in the cortex 3 days after ischaemia/ reperfusion. $\mathrm{n}=6$ mice per group. Data are expressed as mean \pm SEM, ${ }^{\star *} \mathrm{p}<0.01$ (WT MCAO group vs Wip1-KO MCAO group). (C) Quantification of IL-6 and TNF- $\alpha$ in peripheral blood. $\mathrm{n}=8 \mathrm{mice} / \mathrm{group}$. Data are expressed as mean $\pm \mathrm{SEM}$, ${ }^{*} \mathrm{p}<0.05$ (MCAO group vs sham group). (D) Quantification of IL-6 and TNF- $\alpha$ in the ischaemic cortex. $n=8$ mice/group. Data are expressed as mean \pm SEM, ${ }^{* *} p<0.01$ (MCAO group vs sham group). (E) Left: representative dual if staining of CD16-positive and Iba-1-positive cells in the cortex 3 days after lateral cerebroventricular injection and brain ischaemia/ reperfusion. Scale bar: $50 \mu \mathrm{m}$. Right: quantification of CD16positive and Iba-1-positive cells in the cortex on the third day after lateral cerebroventricular injection and brain ischaemia/ reperfusion. $\mathrm{n}=6 \mathrm{mice} / \mathrm{group}$. Data are expressed as mean \pm SEM, ${ }^{* *} p<0.01$ (WT MCAO group vs Wip1-KO MCAO group). (F) Left: representative dual if staining of CD206positive and lba-1-positive cells in the cortex on the third day after lateral cerebroventricular injection and brain ischaemia/ reperfusion. Scale bar: $50 \mu \mathrm{m}$. Right: quantification of CD206-positive and Iba-1-positive cells in the cortex on the third day after lateral cerebroventricular injection and brain ischaemia/reperfusion. $n=6$ mice/group. Data are expressed as mean \pm SEM, ${ }^{* \star *} \mathrm{p}<0.001$ (WT MCAO group vs Wip1-KO MCAO group). Avg, average; Iba-1, ionised calcium-binding adaptor molecule 1; IL, interleukin; KO, knockout; MCAO, middle cerebral artery occlusion; NS, not significant; TNF- $\alpha$, tumour necrosis factor alpha; Wip1, wild-type p53-induced protein phosphatase 1; WT, wild type.

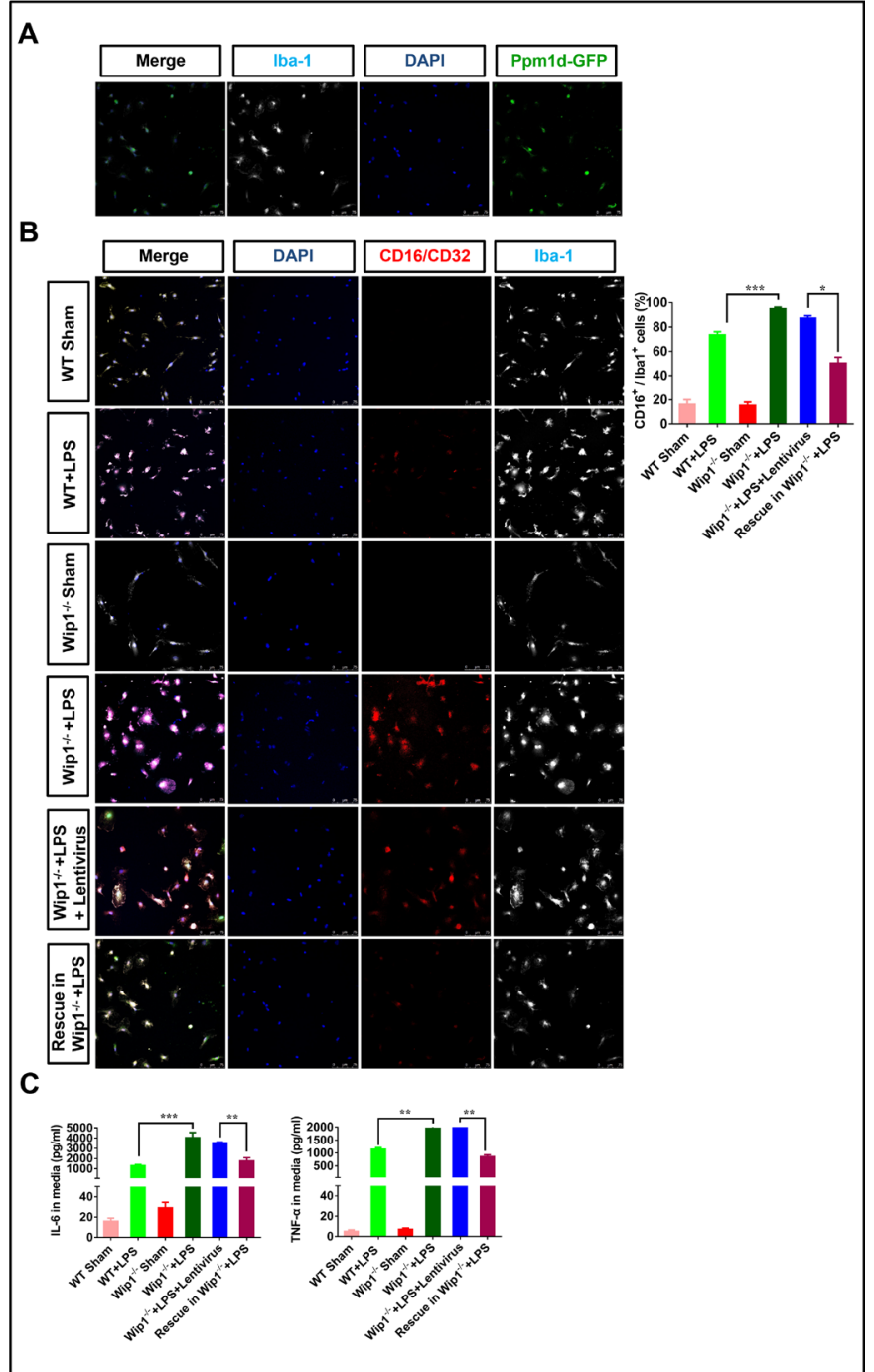

Figure 5 Effect of Wip1 on primary microglial cells after LPS stimulation. (A) Visualisation of Wip1 transfection with GFP expression. (B) Right: representative dual if staining of CD16-positive and Iba-1-positive cells among primary microglial cells after LPS stimulation. Scale bar: $50 \mu \mathrm{m}$. Left: quantification of CD16-positive and Iba-1-positive cells among primary microglial cells after LPS stimulation. $\mathrm{n}=3$. Data are expressed as mean $\pm S E M,{ }^{* * *} \mathrm{p}<0.001$ (WT+LPS group vs Wip1-KO+LPS group); ${ }^{*} p<0.05$ (Wip1KO+LPS+lentivirus group vs Wip1-KO+LPS+lentivirusPpm1d group). (C) Quantification of IL-6 and TNF- $\alpha$ in primary microglial cells after LPS stimulation. $n=3$. Data are expressed as the mean \pm SEM; ${ }^{* *} \mathrm{p}<0.01$ (Wip1$\mathrm{KO}+\mathrm{LPS}+$ lentivirus group vs Wip1-KO+LPS + lentivirusPpm1d group), ${ }^{\star \star *} p<0.001$ (WT+LPS group vs Wip1-KO+LPS group). Iba-1, ionised calcium-binding adaptor molecule 1; IL, interleukin; LPS, lipopolysaccharide; TNF- $\alpha$, tumour necrosis factor alpha; Wip1, wild-type p53-induced protein phosphatase 1.

Wip1 depletion increased neuroinflammation through the NFкB signalling pathway after ischaemia/reperfusion

To further identify the mechanism of inflammatory cytokine upregulation, the effect of Wipl deficiency on

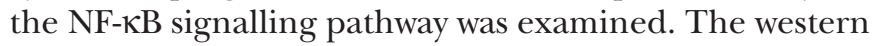




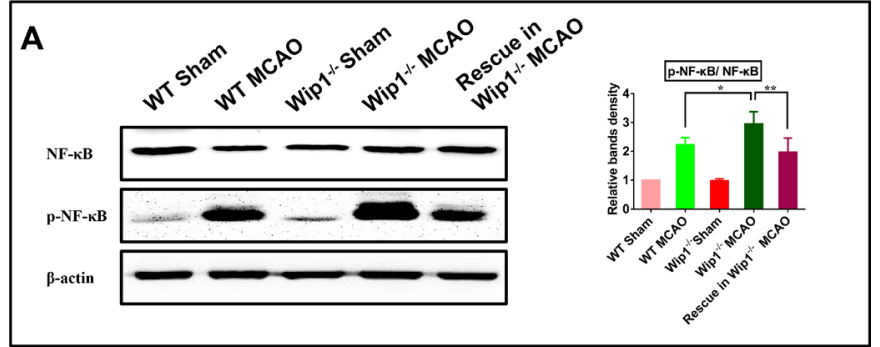

Figure 6 Wip1 deficiency increased neuroinflammation through the NF- $\kappa B$ signalling pathway after ischaemia/ reperfusion. (A) Left: representative western blot images of the expression of NF- $\kappa B$ and $p-N F-\kappa B$. Right: quantification of the expression of NF- $\mathrm{KB}$ and $\mathrm{p}-\mathrm{NF}-\mathrm{\kappa B}$ by western blot analysis. $n=3$ mice/group. Data are expressed as mean \pm SEM; * $\mathrm{p}<0.05$ (WT MCAO group vs Wip1-KO MCAO group), ${ }^{* *} \mathrm{p}<0.01$ (Wip1-KO MCAO group vs Wip1-KO MCAO+lentivirus-Ppm1d group). KO, knockout; MCAO,

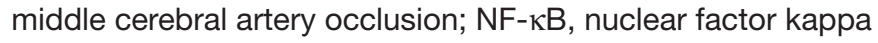
B; Wip1, wild-type p53-induced protein phosphatase 1.

blot results showed that the levels of phospho-NF- $\mathrm{B}$ p65 in Wip1-KO mice were significantly higher than those in WT mice after brain ischaemia/reperfusion. Intracerebroventricular injection of lentivirus-Ppm1d inhibited activation of the $\mathrm{NF}-\kappa \mathrm{B}$ signalling pathway in the Wip1-KO+lentivirus MCAO group (figure 6). These data suggest that upregulation of the NF- $\mathrm{B}$ signalling pathway in Wip1-KO mice might contribute to inflammation after brain ischaemia/reperfusion.

\section{DISCUSSION}

Wipl is an important oncogenic protein that has already been found to be highly expressed in multiple types of tumour cells in original research. ${ }^{24} \mathrm{Wip} 1$ has been recently reported to negatively regulate peripheral inflammation. ${ }^{25}$ In addition, in recent years, an increasing number of studies have begun to focus on the role of Wip1 in the CNS. In our previous study, we found that Wip1 played a critical role in protecting against brain injury under high-altitude hypoxic conditions by regulating the inflammatory reaction. ${ }^{21}$ Wip1-KO enhanced the levels of inflammatory cytokines in brain tissue after high-altitude hypoxic injury. In addition, Qui et al have shown that Wip1-KO downregulates the expression of some proteins in the Wnt/ $\beta$-Catenin signalling pathway 7 days after permanent middle cerebral artery occlusion (pMCAO) ${ }^{26}$ However, the effect of Wip1 on brain ischaemia/reperfusion injury, especially on the brain inflammatory response, remains to be elucidated. In the present study, we found that Wip1 protein levels were obviously increased on the third day after MCAO but had dropped to basal levels by the seventh day after brain ischaemia/reperfusion in the cortex. We examined the infarct volumes on the third and seventh days. Wip1-KO mice exhibited greater infarct volumes than WT mice at these two time points, possibly as a result of neurogenesis induced by Wip1-KO in the late stages. ${ }^{26}$ In addition, Wipl-KO exacerbated brain ischaemia/reperfusion injury by activating microglia and the NF- $\mathrm{NB}$ signalling pathway.

Wip1-KO also increased apoptosis of nerve cells in the acute phase of brain ischaemia/reperfusion and increased mortality in the late stage. These results indicate that Wip1-KO is proapoptotic under ischaemia/ reperfusion conditions. However, Wip1-KO was not found to aggravate neuronal damage in mice in another study. ${ }^{26}$ The reason for the different findings may be that Wip1 was observed in a pMCAO model in the other study. pMCAO always results in more severe injury than temporary MCAO, and the injury is irreversible. Furthermore, Wip1 might be involved in different signalling pathways under different pathological conditions. Many papers have shown that increased levels of inflammation are harmful under ischaemic conditions. ${ }^{27-29}$ Our results suggested that Wip1-KO led to slight increases in TNF- $\alpha$ levels and significant increases in IL-6 levels in brain tissue, but no significant changes in these inflammatory factors were found in the peripheral circulation. These results suggested that the exacerbation of inflammation in the brain was due to increased release of inflammatory factors from brain cells rather than to peripheral inflammation.

Microglia are immune cells that reside in brain tissue and play a key role in regulating brain inflammation after ischaemia/reperfusion. The effect of Wip1 on microglial/macrophage polarisation status after ischaemia/ reperfusion has not been reported previously. Our results strongly indicate that compared with WT conditions, Wip1-KO excessively activated microglia/macrophages in vivo and in vitro and caused more microglia/macrophages to express the M1 phenotype, as indicated by the substantially greater release of proinflammatory factors. On the one hand, excessive activation of microglia can exacerbate inflammation; on the other hand, it can result in excessive release of glutamate, further leading to excitatory neural toxicity and resulting in the death of neurons. However, neuroinflammation is a double-edged sword that is both detrimental and beneficial to neurons. The balance of the physiological role and neurotoxic role of glutamate requires further investigation.

The NF- $\kappa \mathrm{B}$ signalling pathway plays a crucial role in regulating inflammation. Wip1 has been reported to suppress NF- $\kappa \mathrm{B}$ signalling by preventing I $\kappa \mathrm{B}$ dissociation from NF- $\mathrm{B}$ or dephosphorylating the p65 subunit of NF-кB. ${ }^{30-32}$ Classically, activated microglia are also named M1 microglia, which contribute to the generation of various proinflammatory cytokines, such as TNF- $\alpha$ and IL- 6 , by stimulating the NF- $\mathrm{KB}$ signalling pathway. In the present study, we found that Wip1-KO could activate NF- $\mathrm{KB}$ signalling after brain ischaemia/reperfusion, which might be the reason for the increased brain inflammation in Wip1-KO mice after brain ischaemic injury. Interestingly, our results showed that Wip1 depletion had no effect on NF-kB in the Wip1-KO sham group. Normally, $\mathrm{NF}-\kappa \mathrm{B}$ is also regulated by p38, IKK (inhibitor of nuclear factor kappa-B kinase), and other kinases, which might 
be the reason that Wip1 deletion had no significant influence on NF-KB in the Wip1-KO sham group. However, Wip1 can be overexpressed under stress conditions and is thus involved in the DNA repair process and repression of gene expression. However, Wip1 is a phosphatase. Alteration of the phosphorylation status of Wip1 may also play a role in regulating gene expression. More studies are needed to clarify these possibilities.

In summary, the present study is the first to show that Wip1-KO is harmful to the brain after cerebral ischaemia, possibly because it increases the numbers of activated microglia/macrophages and increases brain inflammation after brain ischaemia/reperfusion. Therefore, these results provide new insights regarding the mechanism of brain ischaemia/reperfusion and suggest that the prognosis of stroke may be affected by the regulation of Wip1 expression. Further study is needed to explore whether Wip1 overexpression can exert a neuroprotective effect after ischaemic brain injury and to determine the balanced expression level of Wip1.

Contributors FY performed the certain experiments and wrote the manuscript. FY and XC completed the majority of the experiments. MZ, SG, YH, LD, DW, WZ and YL contributed to the idea and conception of this study. LZ, MF and XJ funded this research, supervised the experiments, and modified the manuscript. All authors read and approved the final manuscript.

Funding This study was funded by Incubation foundation of Capital Medical University (PYZ2018061), Nature and Sciences Foundation of China (81430044, 81974183, 81930054, 82072104).

Competing interests None declared.

Patient consent for publication Not required.

Ethics approval All animal care procedures and experiments were approved by the Committee of Ethics on Animal Experiments of Capital Medical University. All efforts were made to minimise the suffering and numbers of the animals used.

Provenance and peer review Not commissioned; externally peer reviewed.

Data availability statement Data are available upon reasonable request. Data are available upon reasonable request.

Open access This is an open access article distributed in accordance with the Creative Commons Attribution Non Commercial (CC BY-NC 4.0) license, which permits others to distribute, remix, adapt, build upon this work non-commercially, and license their derivative works on different terms, provided the original work is properly cited, appropriate credit is given, any changes made indicated, and the use is non-commercial. See: http://creativecommons.org/licenses/by-nc/4.0/.

ORCID iD

Feng Yan http://orcid.org/0000-0003-3597-6698

\section{REFERENCES}

1 Feigin VL, Krishnamurthi RV, Parmar P, et al. Update on the global burden of ischemic and hemorrhagic stroke in 1990-2013: the GBD 2013 study. Neuroepidemiology 2015;45:161-76.

2 Wei C-C, Kong Y-Y, Hua X, et al. Nad replenishment with nicotinamide mononucleotide protects blood-brain barrier integrity and attenuates delayed tissue plasminogen activator-induced haemorrhagic transformation after cerebral ischaemia. $\mathrm{Br} \mathrm{J}$ Pharmacol 2017;174:3823-36.

3 Jiang $\mathrm{Y}$, Zhang $\mathrm{X}, \mathrm{Mu} \mathrm{H}$, et al. Preparation and evaluation of injectable rasagiline mesylate dual-controlled drug delivery system for the treatment of Parkinson's disease. Drug Deliv 2018;25:143-52.

4 Han B, Hu J, Shen J, et al. Neuroprotective effect of hydroxysafflor yellow A on 6-hydroxydopamine-induced Parkinson's disease in rats. Eur J Pharmacol 2013;714:83-8.

5 Siemian JN, LaMacchia ZM, Spreuer V, et al. The imidazoline $\mathrm{I}_{2}$ receptor agonist ${ }_{2}-\mathrm{BFI}$ attenuates hypersensitivity and spinal neuroinflammation in a rat model of neuropathic pain. Biochem Pharmacol 2018;153:260-8.

6 Aguzzi A, Barres BA, Bennett ML. Microglia: scapegoat, saboteur, or something else? Science 2013;339:156-61.

7 Crotti A, Ransohoff RM. Microglial physiology and pathophysiology: insights from genome-wide transcriptional profiling. Immunity 2016;44:505-15.

8 Tang Y, Le W. Differential roles of M1 and M2 microglia in neurodegenerative diseases. Mol Neurobiol 2016;53:1181-94.

9 Ransohoff RM. A polarizing question: do M1 and M2 microglia exist? Nat Neurosci 2016;19:987-91.

10 Holtman IR, Skola D, Glass CK. Transcriptional control of microglia phenotypes in health and disease. J Clin Invest 2017;127:3220-9.

11 Xin W, Wang Q, Zhang D, et al. A new mechanism of inhibition of IL$1 \beta$ secretion by celastrol through the NLRP3 inflammasome pathway. Eur J Pharmacol 2017;814:240-7.

12 Bai F, Zhou H, Fu Z, et al. NF-kB-induced Wip1 expression promotes colorectal cancer cell proliferation through mTOR signaling. Biomed Pharmacother 2018;99:402-10.

$13 \mathrm{Ma}$ X, Han J, Wu Q, et al. Involvement of dysregulated Wip1 in manganese-induced p53 signaling and neuronal apoptosis. Toxicol Lett 2015;235:17-27.

14 Xiao F-H, Chen X-Q, Yu Q, et al. Transcriptome evidence reveals enhanced autophagy-lysosomal function in centenarians. Genome Res 2018;28:1601-10.

15 Xu F, Chen L, Zhao X, et al. Interaction of Wip1 and NF-kB regulates neuroinflammatory response in astrocytes. Inflamm Res 2017;66:1011-9.

16 Shen X-F, Zhao Y, Jiang J-P, et al. Phosphatase Wip1 in immunity: an overview and update. Front Immunol 2017;8:8.

17 Spychala MS, Venna VR, Jandzinski M, et al. Age-related changes in the gut microbiota influence systemic inflammation and stroke outcome. Ann Neurol 2018;84:23-36.

18 Stary CM, Xu L, Sun X, et al. MicroRNA-200c contributes to injury from transient focal cerebral ischemia by targeting Reelin. Stroke 2015;46:551-6.

19 Liu X, Liu J, Zhao S, et al. Interleukin-4 is essential for microglia/ macrophage M2 polarization and long-term recovery after cerebral ischemia. Stroke 2016;47:498-504.

20 Zhen H, Zhao L, Ling Z, et al. Wip1 regulates blood-brain barrier function and neuro-inflammation induced by lipopolysaccharide via the sonic hedgehog signaling signaling pathway. Mol Immunol 2018;93:31-7.

21 Li D, Zhang L, Huang X, et al. Wip1 phosphatase plays a critical neuroprotective role in brain injury induced by high-altitude hypoxic inflammation. Neurosci Bull 2017;33:292-8.

22 Zhong H, Cui L, Xu F, et al. Up-regulation of Wip1 involves in neuroinflammation of retinal astrocytes after optic nerve crush via NF-kB signaling pathway. Inflamm Res 2016;65:709-15.

23 Du J, Shen X, Zhao Y, et al. Wip1-deficient neutrophils significantly promote intestinal ischemia/reperfusion injury in mice. Curr Mol Med 2015;15:100-8.

24 Park D-S, Yoon G-H, Kim E-Y, et al. Wip1 regulates Smad4 phosphorylation and inhibits TGF- $\beta$ signaling. EMBO Rep 2020;21:e48693.

$25 \mathrm{Du}$ J, Shen X, Zhao Y, et al. Wip1-deficient neutrophils significantly promote intestinal ischemia/reperfusion injury in mice. Curr Mol Med 2015;15:100-8.

26 Qiu C-W, Liu Z-Y, Hou K, et al. Wip1 knockout inhibits neurogenesis by affecting the $W n t / \beta$-catenin signaling pathway in focal cerebral ischemia in mice. Exp Neurol 2018;309:44-53.

27 Niu F-nan, Zhang X, Hu X-ming, et al. Targeted mutation of Fas ligand gene attenuates brain inflammation in experimental stroke. Brain Behav Immun 2012;26:61-71.

28 Hu X, Li P, Guo Y, et al. Microglia/Macrophage polarization dynamics reveal novel mechanism of injury expansion after focal cerebral ischemia. Stroke 2012;43:3063-70.

29 Zhao S, Li F, Leak RK, et al. Regulation of neuroinflammation through programed death-1/programed death ligand signaling in neurological disorders. Front Cell Neurosci 2014;8:271.

$30 \mathrm{Li} \mathrm{C}, \mathrm{He} \mathrm{J}$, Gao Y, et al. Preventive effect of total flavones of Choerospondias axillaries on ischemia/reperfusion-induced myocardial infarction-related MAPK signaling pathway. Cardiovasc Toxicol 2014;14:145-52.

31 Gao Y, Jiang W, Dong C, et al. Anti-inflammatory effects of sophocarpine in LPS-induced RAW 264.7 cells via NF-KB and MAPKs signaling pathways. Toxicol In Vitro 2012;26:1-6.

32 Gao Y, Kang L, Li C, et al. Resveratrol ameliorates diabetes-induced cardiac dysfunction through AT1R-ERK/p38 MAPK signaling pathway. Cardiovasc Toxicol 2016;16:130-7. 